\title{
Pays bourguignons et Orient: diplomatie, conflits, pèlerinages, échanges (XIV ${ }^{e}-\mathrm{XVI}^{\mathrm{e}}$ siècles)
}

\section{Maria Colombo Timelli}

\section{(2) OpenEdition}

\section{Journals}

Édition électronique

URL : http://journals.openedition.org/studifrancesi/9897

DOI : 10.4000/studifrancesi.9897

ISSN : 2427-5856

Éditeur

Rosenberg \& Sellier

Édition imprimée

Date de publication : 1 août 2017

Pagination : 337-338

ISSN : 0039-2944

\section{Référence électronique}

Maria Colombo Timelli, «Pays bourguignons et Orient: diplomatie, conflits, pèlerinages, échanges $\left(x v^{\mathrm{e}}-\mathrm{xv}\right]^{\mathrm{e}}$ siècles) », Studi Francesi [En ligne], 182 (LXI | II) | 2017, mis en ligne le 01 août 2017, consulté le 06 janvier 2021. URL : http://journals.openedition.org/studifrancesi/9897 ; DOI : https://doi.org/10.4000/ studifrancesi.9897

Ce document a été généré automatiquement le 6 janvier 2021.

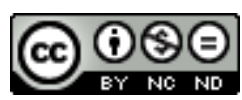

Studi Francesi è distribuita con Licenza Creative Commons Attribuzione - Non commerciale - Non opere derivate 4.0 Internazionale. 


\title{
Pays bourguignons et Orient: diplomatie, conflits, pèlerinages, échanges (XIV $-\mathrm{XVI}^{\mathrm{e}}$ siècles)
}

\author{
Maria Colombo Timelli
}

\section{RÉFÉRENCE}

Pays bourguignons et Orient: diplomatie, conflits, pèlerinages, échanges (XIV ${ }^{e}-\mathrm{XVI}{ }^{e}$ siècles), Rencontres de Mariemont-Bruxelles, 24-27 septembre 2015, «Publications du Centre Européen d'Études Bourguignonnes (XIV ${ }^{\mathrm{e}}-\mathrm{XVI}^{\mathrm{e}} \mathrm{s}$. )» 56, 2016.

1 Les relations entre la Bourgogne et les pays d'Outre-Mer furent fréquentes notamment sous les ducs Valois, sous des formes différentes: aux pèlerinages s'ajoutent en effet des missions diplomatiques et des voyages d'exploration destinés en particulier à soutenir le projet de Croisade que Philippe le Bon caressa tout au long de sa vie. Ce recueil fait le point sur ces aspects dans des perspectives complémentaires: historique, artistique, littéraire, voire militaire.

2 Jacques PAVIOT s'intéresse d'abord aux voies par lesquelles parvenaient à la cour des Ducs les informations sur l'Orient: comptes rendus d'ambassades ou de pèlerinages, échanges épistolaires avec des Franciscains, contacts individuels; les chroniqueurs - de Froissart à Chastelain - fournissent aussi dans ce domaine une grande quantité de renseignements (Les "Nouvelles de Levant" à la cour de Bourgogne, pp. 27-39; tableau chronologique des évènements aux pp. 35-39). Dans une perspective analogue, Jaroslav SVÁTEK met en relief un aspect particulier du Voyage d'outremer (1432-1433), à savoir l'attention que Bertrandon de La Broquière réserve aux structures étatiques de l'Asie Mineure et son émerveillement vis-à-vis de la cour ottomane et de son fonctionnement (L'idéal du souverain oriental dans le récit de Bertrandon de La Broquière, pp. 61-72); alors que Bernard HAQUETTE propose une étude centrée sur les pèlerinages en Terre Sainte entrepris par la famille de La Viesville, et pense pouvoir attribuer un récit de voyage 
(entre 1419 et 1425) jusque-là anonyme à Pierre IV de la Viesville (Pèlerins artésiens en Terre Sainte à la fin du Moyen Âge, pp. 161-173). Marie-Cécile BRUWIER, Gilles DOCQUIER, Alain MARCHANDISSE font bien plus qu' «esquisser» une lecture du compte rendu que Georges Lengherand, dignitaire montois, a laissé de son voyage en Terre Sainte: ils soulignent l'intérêt des pages consacrées à l'itinéraire italien, puis à la traversée du Sinaï («En tous quartiers ou j'ay esté». Le récit de pèlerinage de Georges Lengherand, mayeur de Mons (1486-1487): une esquisse, pp. 191-211).

3 Avec Gisela NAEGLE on aborde deux moments qui ont marqué l'histoire bourguignonne: d'une part la défaite de Nicopolis (1396) dans l'œuvre de Philippe de Mézières, d'autre part la chute de Constantinople (1453) et les réactions que celle-ci provoqua, au-delà du Duché, dans plusieurs pays européens (Pleurer, convaincre et reformer. Défaites militaires, projets de croisade et réformation du monde dans l'espace bourguignon (XIV ${ }^{e} X V^{e}$ siècles), pp. 41-59). Nicopolis revient aussi dans la contribution de Bertrand SCHNERB, qui retrace la biographie d'Enguerran VII de Coucy, fait prisonnier par les Turcs en 1396 et mort en captivité l'année suivante: Eustache Deschamps, qui lui fut proche, en fait le portrait dans certains de ses poèmes, parmi lesquels la complainte composée pour sa mort, des ballades et des rondeaux (Vie et mort d'un combattant de Nicopolis: Enguerrand VII, seigneur de Coucy, pp. 83-105).

4 L'opposition apparente entre Bourgogne et monde oriental s'estompe parfois, comme le montrent les Chroniques de Jean de Wavrin et le Gazavatnâme anonyme, dédié au sultan Murad II, objet de la contribution de Hilmi KAÇAR: les portraits du souverain idéal qui ressortent de ces deux textes présentent en effet des similarités saisissantes (A Comparison of Ottoman and Burgundian Narratives on the Battle of Varna (1444), pp. 73-81).

Le voyage d'Outre-Mer et les motifs qui lui sont associés trouvent enfin une illustration extraordinaire dans Othovien, remaniement en prose de Florent et Octavien achevé juste après le Banquet du Faisan. Matthieu MARCHAL en examine les particularités: la précision géographique, qui semble venir des récits de voyage, l'assimilation de l'empereur de Rome, défenseur de la chrétienté, à Philippe le Bon, le vénération pour les Lieux Saints et surtout le désir de reconquérir la Terre Sainte. Mise à jour d'une chanson de geste récente (les manuscrits datent du milieu du $\mathrm{xv}^{\mathrm{e}}$ siècle), Othovien porte l'empreinte des préoccupations bourguignonnes après la chute de Constantinople (Voyages et conflits militaires au Proche-Orient dans la mise en prose bourguignonne de "Florent et Octavien", pp. 145-159).

D'autres articles portent sur les contacts entre les milieux bourguignons et l'Orient dans des perspectives plus techniques ou étrangères à la culture proprement française: l'intérêt des Orientaux à l'égard des Bourguignons (Jean-Charles DucÈNe, Les Pays-Bas bourguignons dans les sources orientales, pp. 17-26), le reflet de l'Orient dans l'œuvre picturale de Jan Van Eyck (Ludovic NYS, Jean Van Eyck et Jérusalem, pp. 107-126), l'attention de Philippe le Bon pour les armes des Turcs (Michael DEPRETER, "A la faiçon de Turquie”. Philippe le Bon et l'artillerie ottomane: de l'admiration à la désillusion?, pp. 127-144), des récits de voyage en moyen néerlandais (Alexia LAGAST, Polémique ou neutralité? La représentation de Mahomet dans les récits de voyage de Josse de Ghistelles (1481-1485) et de Bernhard von Breydenbach (1483-1484), pp. 175-189), des missions diplomatiques plus tardives (Louis SICKING, L'origine de la diplomatie impériale à la cour ottomane. Les missions de Corneille de Schepper, ambassadeur habsbourgeois, à Constantinople, 1533-1534, pp. 213-239). 